\title{
Recuperação Populacional e Fecundidade dos Kamaiurá, Povo Tupi do Alto Xingu, Brasil Central, 1970-2003
}

\section{Population Recovery and Fertility Among the Kamaiurá, Tupi People of the Alto Xingu, Central Brazil, 1970-2003}

\author{
Heloisa Pagliaro \\ Demógrafa, Doutora em Saúde Publica, Pesquisadora, Disciplina \\ de Epidemiologia, Departamento de Medicina Preventiva, \\ Universidade Federal de São Paulo/Escola Paulista de Medicina. \\ Endereço: UNIFESP. Rua Borges Lagoa,1341, Vila Clementino, cep \\ 04038-034, São Paulo, SP, Brasil \\ E-mail: pagliaroळmedprev.epm.br

\section{Carmen Junqueira} \\ Antropóloga, Doutora em Antropologia, Professora Emérita da \\ Pontifícia Universidade Católica de São Paulo. \\ E-mail: carmen.junqueiraळterra.com.br
}

\section{Resumo}

Este trabalho analisa a fecundidade dos Kamaiurá, povo Tupi habitante do Parque Indígena do Xingu (PIX), entre 1970 e 2003. As fontes de dados foram os registros do Programa de Saúde da Universidade Federal de São Paulo (Unifesp) no Parque Indígena do Xingu e levantamentos de campo realizados em 2003. O estudo mostrou que até 1966 a população Kamaiurá manteve-se estável devido à alta mortalidade por epidemias de doenças infecciosas e disputas com os povos da região, assim como à fecundidade moderada. Entre 1967 e 2002, essa população cresceu 3,5\% ao ano. 0 nível da fecundidade das Kamaiurá passou de 5,7 para 6,2 filhos por mulher, entre 1970 e 2003, tendo atingido seu valor máximo em $1980(6,6)$. A partir da década de 1990, houve um envelhecimento do padrão reprodutivo, evidenciado pela redução dos níveis de fecundidade das mulheres com até 24 anos e aumento entre as mulheres dos demais grupos etários. A média de idade ao nascimento do primeiro filho aumentou de 16,2 para 18,8 anos, no período 19702003, e a proporção de mulheres solteiras maiores de 15 anos de idade também cresceu: de 6,3\%, em 1971, para $26 \%$, em 2003. Nesse período, o intervalo entre os nascimentos variou entre 30,3 e 36 meses. 0 aumento da fecundidade dos Kamaiurá foi favorecido pela melhoria das condições de saúde decorrente da queda da mortalidade, mas ocorreu sem o abandono de suas práticas tradicionais de controle da natalidade, o que lhes permitiu crescer de forma racional e equilibrada.

Palavras-chave: Fecundidade dos Kamaiurá; Recuperação populacional dos povos indígenas; Índios das Terras Baixas da América Latina; Demografia dos povos indígenas; Povos indígenas do Brasil Central. 


\section{Abstract}

This paper analyses the fertility of the Kamaiurá, a Tupi people that inhabits the Xingu Indigenous Park (XIP), between 1970 and 2003. Data has been gathered from medical records of the Health Program of the São Paulo Federal University (Unifesp) at XIP, and from a survey conducted at the Kamaiurá village in 2003. Results have shown that before 1966, high mortality rates due to disputes among the indigenous nations of the region and contagious diseases, as well as moderate fertility levels were responsible for the stability trend of the population. The average population growth between 1967 and 2003 was 3.5\%. Total fertility rates increased from 5.7 to 6.2 births per woman, between 1970 and 2003, reaching their highest level in 1980 (6.6). Since the 1990 os there has been an ageing of the reproductive patterns, with the decrease of fertility levels among women up to 24 years of age, and an increase among women in the other age groups. The average age at first birth increased from 16.2 to 18.8 years between 1970-2003; the proportion of single women older than 15 years also increased: from $6.3 \%$ in 1971 to $26 \%$ in 2003 ; the inter-birth intervals varied between 30.3 and 36 months. The increase in the Kamaiurá's fertility rate was favored by the decrease in general and infant mortality rates, but the Kamaiurá did not abandon their traditional fertility controls, which has allowed a rational and balanced population growth.

Keywords: Kamaiurá's Fertility; Indigenous Population Growth; Indigenous Population in the Lowlands of Latin America; Demography of Indigenous People; Indigenous People of Central Brazil.

\section{Introdução}

Estimada em de 800 mil e 5 milhões de indivíduos pertencentes a mais de mil grupos étnicos diferentes em 1500, a população indígena no Brasil decresceu continuamente até o princípio do século XX, reduzindo-se a aproximadamente 300 mil habitantes no ano de 1900 (Kennedy \& Perz, 200o; Hemming, 1978; Gomes, 1981, 2002). Para a década de 1950, Ribeiro (1957) estimou o número de habitantes das nações indígenas no país em cerca de 100 mil indivíduos, prevendo a sua redução progressiva ou provável extinção.

As perspectivas de provável desaparecimento dos povos indígenas no país perduraram até 1970, quando indícios de crescimento de alguns povos sinalizaram a reversão dessa tendência (Gomes, 1981; Melatti, 1999). Estimativas mais recentes, da Fundação Nacional do Índio (Funai, 20o6) órgão do Ministério da Justiça, apontam a existência de 450 mil índios, pertencentes a mais de 200 etnias e falantes de aproximadamente 180 línguas.

Estudos antropológicos e demográficos sobre povos indígenas específicos (Pagliaro e col., 2005) confirmam que alguns grupos experimentaram flutuações nos níveis de mortalidade e de natalidade nas últimas décadas, que em longo prazo tiveram um efeito uniforme, resultando em crescimento positivo. Alguns povos têm crescido em média 3,5\% ao ano (Ricardo, 2005), ou quase o dobro do conjunto da população brasileira, que cresceu 1,64\% ao ano no período 1991-200o (IBGE, 2004). Não obstante, alguns povos isolados ainda são vítimas de violências e de doenças, correndo o risco de desaparecerem.

0 crescimento observado entre esses povos teria ocorrido em razão da combinação da queda da mortalidade e do aumento ou manutenção da fecundidade em níveis elevados, ou seria fruto de uma recuperação demográfica racional, na qual estaria implícita a percepção desses povos em relação ao processo de decréscimo populacional vivenciado desde a chegada dos colonizadores ao Brasil? Estudos etno-demográficos realizados nas décadas de 1940 a 1970, visando avaliar os efeitos do despovoamento sobre a organização social das sociedades indígenas no Brasil, provocados pelos contatos com as diferentes frentes expansionistas, mostraram que povos que não conheciam práticas de restrição voluntária da natalidade 
puderam alcançar relativa estabilidade populacional e garantir sua sobrevivência apesar dos altos níveis de mortalidade que experimentavam, ao passo que outros conhecedores dessas práticas anulavam seu potencial de crescimento (Wagley, 1942 e 1951). Ribeiro (1956), que observou 13 povos após situações de contato com a sociedade envolvente mostrou que fatores estruturais próprios da organização social dessas populações estariam associados ao seu comportamento demográfico. $\mathrm{O}$ autor concluiu que alguns povos recuperaram a população anterior ao contato e que outros, conhecedores de práticas contraceptivas e praticantes do aborto e do infanticídio, em situações de desorganização social, não puderam enfrentar o despovoamento.

As relações entre sistemas culturais e regimes demográficos vêm sendo exploradas para explicar as modificações ocorridas no comportamento da fecundidade de diferentes sociedades, mostrando como a utilização de conhecimentos antropológicos pode contribuir para ampliar a compreensão de processos populacionais (Das Gupta, 1997). Os diferentes sistemas familiares e de parentesco e as complexas regras de casamento e de residência, os padrões de idade ao casar e ao dar a luz ao primeiro filho, as normas relativas à concepção e contracepção, o intervalo entre os nascimentos, o tempo de aleitamento, dentre tantos outros, são aspectos da cultura dos povos que têm considerável influência nos regimes demográficos experimentados pelas diferentes sociedades, principalmente as de pequena escala. 0 trabalho de Davis \& Blake (1967) abriu caminho para a consideração sistemática entre fecundidade e variáveis socioculturais e a ele se seguiram inúmeros outros, buscando associar o comportamento reprodutivo a aspectos sociais e econômicos.

No intuito de buscar explicações para a recente reversão da tendência de declínio populacional de alguns povos indígenas no Brasil, demógrafos e antropólogos têm sido motivados a retomar as discussões acerca da relação entre os modelos culturais, as formas de interação com a sociedade envolvente e os regimes demográficos vigentes entre esses povos, iniciadas por Wagley (1942 e 1951), Ribeiro (1956) e outros autores nas décadas de 1940 e 1950 (Pagliaro e col., 2005). Um aspecto importante dessa discussão é a compreensão das relações entre processo reprodu- tivo e as diferentes formas de organização social dos povos indígenas. Esse foi o foco de Camargo e col. (2005), em pesquisa realizada em 1970, sobre a fecundidade das mulheres Kamaiurá (MT), e os aspectos qualitativos das variáveis intermediárias da fecundidade, conforme os preceitos teóricos propostos por Davis e Blake (1967). Nessa mesma linha de estudo, Meirelles (1988) comparou dados qualitativos sobre os padrões reprodutivos dos Karitiana, Gaviões e Pakaas-Novos, pressupondo que modificações na organização social dessas populações resultariam em variações de seus padrões de fecundidade. Ao interpretar as variações da fecundidade das mulheres Mekranoti-Kayapó, Werner (1983) identificou os aspectos culturais e demográficos que causaram a flutuação dos seus níveis de fecundidade no período de 1930 a 1970. Early e Peters (1990) estudaram o comportamento demográfico dos Yanomama do rio $\mathrm{Mu}$ cajai, com dados de um período de 27 anos, avaliando aspectos do seu comportamento reprodutivo e cultural. Em análise demográfica sobre os Xavante de Pimentel Barbosa, Flowers (1994) estimou as tendências da fecundidade para o período de 1942 a 1990, pontuando aspectos etnográficos e da história de contato desse povo com a sociedade envolvente. Greene e Croker (1994) avaliaram a relação entre níveis de fecundidade e uniões poligâmicas entre os Canela, no período entre 1970-1988. Picchi (1994) discutiu os níveis de fecundidade dos Bakairi, no período entre 1979-1989, relacionando-os a algumas variáveis intermediárias. Pagliaro (2002 e 2005) estimou os níveis e os padrões de fecundidade das mulheres Kaiabi por períodos de tempo (1970-1999) e segundo coortes retrospectivas, relacionando seus achados a aspectos socioculturais desse povo. Azevedo (2004) estimou os níveis de fecundidade de diversos povos do Alto Rio Negro, entre 1990-1992, relacionando-os ao tipo de casamento desses povos determinado por exogamia lingüística.

Em estudo demográfico sobre os Kamaiurá, Pagliaro e col. (2004) realizaram uma análise da dinâmica dessa população entre 1948 e 2002, com ênfase nas características, padrões e tendências observados entre 1970 e 1999, período para o qual os autores dispunham de maior detalhamento das informações. Os autores observaram que a alta mortalidade ocasionada por epidemias de doenças contagiosas e a manu- 
tenção de um padrão de família relativamente pequeno determinaram a estabilidade do volume populacional, em torno de 110 habitantes, durante os anos de 1948 a 1966. No período 1967-2002, a população Kamaiurá cresceu 3,5\% ao ano, sendo de 378 habitantes em 2002. 0 aumento vegetativo foi o fator responsável por esse ritmo de crescimento, sendo negativo o saldo migratório resultante dos casamentos interétnicos. Os níveis de natalidade variaram de 35,2 a 45,7 nascimentos por mil habitantes, ficando em torno de 40\%o, em media, no período de 1970 a 1999. Apesar das dificuldades advindas do pequeno volume populacional e da sub contagem de óbitos, devido à prática cultural do infanticídio e as dificuldades em registrar esses eventos, os autores observaram que entre 19701999 os níveis de mortalidade geral oscilaram entre 5 e 10 óbitos por mil habitantes, sendo a mortalidade no sexo masculino maior do que no feminino. Ainda nesse período, a taxa média de mortalidade infantil foi de 18,3 óbitos por mil nascidos vivos (excluídos os infanticídios). A estrutura etária da população manteve-se jovem, sendo $47 \%$ da população constituída de menores de 15 anos de idade e $11 \%$ de maiores de 50 anos (Pagliaro e col., 2004).

Nesse contexto, buscando contribuir para a ampliação dos conhecimentos no campo da demografia indígena no Brasil e pressupondo que o processo de recuperação demográfica dos Kamaiurá tenha sido gerado também por mudanças em seu comportamento reprodutivo, este trabalho tem o objetivo de identificar modificações no padrão de fecundidade desse povo, nas três décadas que separam a realização do primeiro estudo desse tipo, em 1971, por Camargo e col. (2005), considerando aspectos da sua organização social que intermediariam o comportamento reprodutivo.

\section{Os Kamaiurá}

Os Kamaiurá são um povo de língua Tupi que, juntamente com outros nove povos das famílias linguísticas Aruak, Karib, Tupi e da língua isolada Trumai, habitam a região do Alto Xingu, Mato Grosso, Brasil Central. A homogeneidade cultural desses povos é evidenciada em múltiplos aspectos, como a forma e a disposição das aldeias, o tipo de habitação, os hábitos alimentares, a reclusão pubertária, a prática de infanticídio, as pinturas e os adornos corporais, o uso do uluri (pequeno cinto pubiano) pelas mulheres, as festas e as cerimônias. Esse padrão cultural comum teria resultado da longa ocupação de uma mesma área geográfica e da freqüência de casamentos interétnicos (Öberg, 1953; Galvão, 1979; Junqueira, 1978).

O primeiro contato dos Kamaiurá com representantes da "civilização ocidental" ocorreu em 1887, com a expedição de Karl von den Steinen (1940), que os encontrou nas proximidades da lagoa do Ipavu, no Alto Xingu. Daí por diante, várias expedições penetraram a região em visitas intermitentes e de curta duração. Em 1942, com a criação do órgão público, Fundação Brasil Central (FBC), iniciou-se a abertura de estradas e o estabelecimento de acampamentos na área (Villas Bôas, 1994). Em 1946 eles foram atingidos por essa penetração e passaram a ter contatos regulares com os membros da expedição RoncadorXingu, da FBC. Em 1961, o território que habitavam tornou-se o Parque Nacional do Xingu, sendo hoje denominado Parque Indígena do Xingu (PIX), subordinado à Fundação Nacional do Índio (Funai).

\section{Material e Métodos}

Para mensurar a fecundidade das mulheres Kamaiurá utilizou-se o modelo de análise transversal ou por períodos. Esse tipo de análise permitiu captar os níveis e os padrões de fecundidade em diversos momentos do período de 1970-2003. Para contornar as flutuações dos indicadores estimados, resultantes do pequeno volume populacional foram calculados indicadores médios para períodos de dez anos entre 1970 e 1999, e de quatro anos a partir de 2000. As medidas utilizadas foram: taxas específicas de fecundidade por idade da mãe (TEF), taxas de fecundidade total (TFT), idade média de fecundidade, médias de idade das mães ao nascimento do primeiro filho e intervalo entre os nascimentos (intergenésico). Os indicadores foram estimados por meio de técnica direta, visto que os dados provêm de um registro contínuo de eventos vitais.

Os dados utilizados foram extraídos das fichas médicas e dos livros de registro de eventos vitais do Programa de Saúde da Universidade Federal de São Paulo (Unifesp/EPM), no Parque Indígena do Xingu, os quais são alimentados regularmente, desde sua implantação em 1965 (Baruzzi, 2005).

As fichas médicas contêm, além das informações 
de saúde, o número de registro no programa de saúde, fotografias de identificação na infância, adolescência, idade adulta e velhice; etnia; data de abertura da ficha, data de nascimento, estimada pela equipe médica que realizou o primeiro exame clínico dos indivíduos nascidos antes da implantação do Programa e real para os nascidos a partir de 1965; os diferentes nomes que os indivíduos recebem durante os ciclos de vida; sexo; data de óbito, local e causa de morte; nome dos pais e cônjuge(s); localidade ou aldeia de residência e eventuais mudanças; nome e número de registro dos filhos.

Os livros de registro de eventos vitais possuem informações sobre os nascimentos e os óbitos ocorridos desde a implantação do sistema, ou seja, número de registro no programa de saúde, nome, sexo, mês e ano de nascimento, etnia, data de abertura da ficha médica, número e nomes dos pais, quando conhecidos, mês e ano do óbito, se ocorreu, e causa de morte. O conteúdo desta fonte de dados foi cotejado com as informações coletadas nas fichas médicas, permitindo a obtenção do universo da população Kamaiurá.

Algumas características da organização sociocultural dos Kamaiurá, que influenciam o seu padrão reprodutivo, também foram descritas: a formação e a dissolução das uniões, o celibato permanente, o intervalo entre as uniões, a abstinência sexual voluntária, a concepção e a contracepção, incluindo a prática de aborto e infanticídio e o tempo de aleitamento. $\mathrm{O}$ que foi possível mensurar em relação a essas variáveis baseou-se nos diários de campo de C. Junqueira, que estuda os Kamaiurá há mais de três décadas, nos levantamentos de campo realizados na aldeia Kamaiurá nos meses de julho e setembro de 2003 e nos docu- mentos do arquivo do Programa de Saúde da Unifesp no Xingu.

\section{Evolução dos Níveis e dos Padrões Etários da Fecundidade}

A evolução dos níveis de fecundidade das mulheres Kamaiurá pode ser observada por meio das Taxas de Fecundidade Total (TFT), medida demográfica de momento, estimadas para os períodos 1970-1979, 19801989, 1990-1999 e 2000-2003. A análise desse indicador mostrou que a fecundidade dessas mulheres aumentou de 5,7 para 6,6 filhos, em média, por mulher, entre as décadas de 1970 e 1980, apresentando ligeira tendência de declínio até os anos de 2000 a 2003 (Tabela 1).

As modificações nos níveis e dos padrões de fecundidade dessas mulheres podem ser observadas em maior detalhe por meio da distribuição percentual da série de taxas específicas de fecundidade por grupos etários (TEF) dos quatro sub-períodos investigados, representadas na Figura1.

Os traçados das curvas de fecundidade mostram que o aumento verificado na década de 1980 ocorreu em quase todas as idades, com exceção do grupo de 10 a 14 anos, sem que houvesse mudanças no padrão reprodutivo. A partir da década de 1990, configurouse um envelhecimento do padrão etário da fecundidade, caracterizado pela diminuição dos níveis de fecundidade das mulheres de 15 a 24 anos (além dos 10 a 14 anos, em 2000-2003), estabilidade nas idades de 25 a 29 anos e maior concentração no grupo de 30 a 34 anos. Esse último grupo etário passou a ser o de maior intensidade de fecundidade na década de 1990 e nos anos 2000-2003.

\section{Tabela I - Indicadores da fecundidade atual das mulheres Kamaiurá, 1970 - 2003}

\begin{tabular}{|c|c|c|c|c|}
\hline Indicadores & $1970-1979$ & $1980-1989$ & $1990-1999$ & $2000-2003$ \\
\hline Taxas de fecundidade total (TFT) das mulheres de 10 a 44 anos & 5,4 & 6,6 & 6,4 & 6,2 \\
\hline Contribuição das mulheres " de 20 anos para a fecundidade total & 27,7 & 21,7 & 15,3 & 13,2 \\
\hline Contribuição das mulheres " de 30 anos para a fecundidade total & 72,0 & 65,0 & 56,1 & 52,0 \\
\hline Contribuição das mulheres " de 30 anos para a fecundidade total & 28,0 & 35,0 & 43,9 & 48,0 \\
\hline Idade média da fecundidade (em anos) & 24,4 & 24,4 & 26,4 & 26,4 \\
\hline Média de idade ao nascimento do I filho (em anos) & 16,2 & 17,8 & 17,8 & 18,8 \\
\hline Intervalo entre os nascimentos (em meses) & 30,3 & 33,3 & 35,4 & 36,0 \\
\hline
\end{tabular}

Fonte de dados brutos: Arquivo do Programa de Saúde da Unifesp no PIX, DMP/UNIFESP/EPM 


\section{Figura I - Distribuição proporcional das taxas de fecundidade por grupos etários das mulheres Kamaiurá, $1970-2003(\%)$}

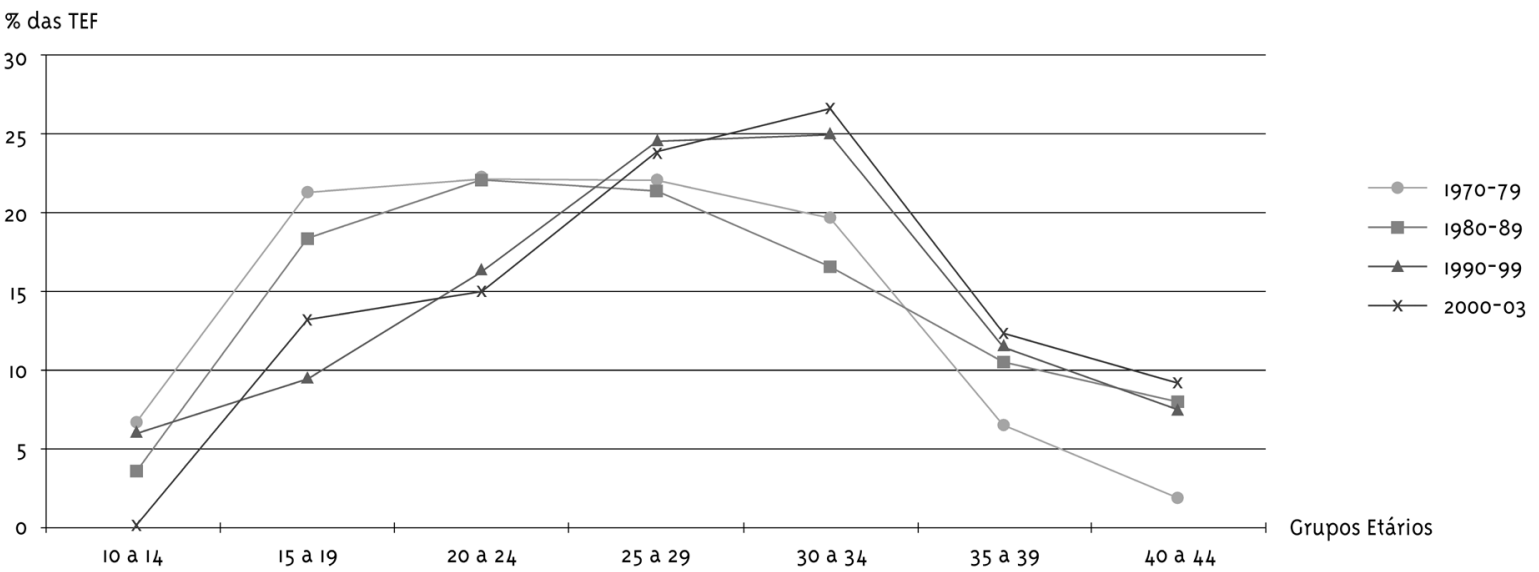

A evolução da fecundidade dessas mulheres para um padrão mais tardio, com concentração nos grupos 25-29 anos e 30-34 anos, seria coerente com o aumento dos níveis de fecundidade e com o aumento da idade média de fecundidade, de 24,4 anos nas décadas de 1970 e 1980, para 26,6 anos na década de 1990 e nos anos 2000-2003 (Tabela 1).

Ainda no tocante ao envelhecimento do padrão da fecundidade por idades, verificou-se que a participação da fecundidade das mulheres com até 20 anos de idade diminuiu, de 27,7\% em 1970, para 13,2 em 20002003 e que a das mulheres com até 30 anos de idade também declinou, de $72 \%$ para $52 \%$, nesse mesmo período (Tabela 1). Os demais grupos etários, ao contrário, aumentaram a sua participação. As medias de idade ao nascimento do primeiro filho aumentaram de 16,2 anos, na década de 1970, para 18,8 anos, no período 2000-2003. O intervalo médio entre os nascimentos variou de 30 a 36 meses, oscilando entre 1970-2003 (Tabela 1).

\section{Padrões socioculturais e comportamento re- produtivo}

As normas relativas à formação das uniões entre os Kamaiurá tenderiam a favorecer uma alta fecundidade, quer pelo início precoce do casamento quer pela facilidade na contratação de novo casamento. As mulheres Kamaiurá casam-se logo após o período de reclusão pubertária, que tem início após a primeira menstruação e se prolonga ao máximo por um ano. Ao sair, com novo nome, são consideradas adultas e prontas para o casamento (Junqueira, 1978, 2002).
Idealmente, as regras de residência dos Kamaiurá definem que nos primeiros anos de casamento o marido deve residir na casa dos pais da esposa (matrilocal). Cumprido esse período, o casal tem liberdade de escolher nova residência, que em geral é a casa de origem do marido (patrilocal). Essa regra, entretanto, não se aplica aos homens donos de casa ou àqueles já casados e que estão constituindo família poligínica. Nessas situações é sempre a mulher que passa a residir na casa do marido.

O casamento preferencial é, idealmente, entre primos cruzados, considerados como parentes classificatórios e não consangüíneos como os primos paralelos. Em nível da geração de uma determinada pessoa, primos cruzados são os filhos das irmãs de seu pai e das irmãs de sua mãe. Cumpra-se ou não as regras de casamento, as alianças com outras casas são sempre efetivadas. Vez por outra, busca-se atender às duas exigências. Os Kamaiurá, seja para fazer frente à desproporção entre os sexos ou por razões outras, estabelecem alianças com os demais povos alto-xinguanos, fazendo surgir entre eles obrigações sociais baseadas no parentesco (Junqueira, 1978, 2002)

Um casamento só é considerado integralmente consumado quando nasce o primeiro filho do casal. Neste sentido, a média de idade das mães ao nascimento do primeiro filho poderia ser uma referência às idades de início das uniões consumadas.

Há na cultura Kamaiurá uma expectativa generalizada de que todas as pessoas devem se casar. 0 casamento, além das funções de procriação e de natureza sexual, torna-se igualmente necessário por razões 
econômicas, decorrentes da divisão sexual do trabalho (Junqueira, 1978). Durante o trabalho de campo na aldeia Kamaiurá, em 2003, observou-se que dentre as 73 mulheres maiores de 15 anos de idade, $26 \%$ ainda permaneciam solteiras. As proporções de solteiras eram de 70,6\% no grupo 15-19 anos, 31,3\% de 20-24 anos e $20 \%$ de $25-29$ anos. Entre as mulheres com idades superiores a 30 anos, apenas duas permaneciam solteiras, em razão de problemas de saúde.

A ruptura da união não impede a contratação imediata de novo casamento. A morte de um cônjuge, entretanto, obriga o sobrevivente a um período considerado de luto, cuja duração varia, no qual ele não pode se casar novamente (Junqueira, 1978). Em 2003, as mulheres separadas ou viúvas, que ainda não haviam se casado novamente, correspondiam, respectivamente, a $8,2 \%$ e $1,4 \%$, do total de mulheres maiores de 15 anos de idade.

Os casais mantêm relações sexuais freqüentes até que a mulher engravide. À medida que a gravidez progride, a freqüência das relações sexuais diminui. No final da gravidez, a vida sexual do casal se interrompe, para recomeçar quando o filho começa a andar (Junqueira 2002). Quanto aos homens, há restrições ao relacionamento sexual dos pajés durante seu período de iniciação e dos lutadores nas competições cerimoniais.

As crianças são amamentadas por período variado de tempo, mas geralmente bastante longo, chegando até três anos (Junqueira, 1978). Com isso, a fecundidade das mulheres diminui consideravelmente nesse espaço de tempo. 0 desmame é gradual e durante este período a criança nunca é impedida de mamar.

Os Kamaiurá afirmam ter conhecimento de ervas capazes de evitar a concepção e que seriam propriamente anticoncepcionais. Não nos foi possível ainda realizar uma análise farmacológica e experimentos suficientes para controlar a veracidade dessa crença (Junqueira, 1978, 2002).

Em algumas situações sociais a cultura Kamaiurá legitima o abortamento. Geralmente o status da mulher constitui o fundamento para a decisão de abortar. As mulheres sem marido ou cujo marido tenha estado ausente por um período longo de tempo recorrem a práticas abortivas. 0 padrão de liberdade sexual extraconjugal pode ocasionar concepção indesejável, que é, portanto, interrompida. Seja por meio de processos mecânicos, ou por meio de ervas, as mulheres
Kamaiurá praticam efetivamente o abortamento (Junqueira, 1978, 2002).

O infanticídio, como forma eticamente aceita para impedir a sobrevivência do recém-nascido, justificase no caso de espaçamento muito curto entre um filho e outro (cuidados e aleitamento prolongado), do nascimento de gêmeos, de crianças malformadas ou nascidas de uniões instáveis, como a de jovens solteiras, de separação do casal antes do nascimento da criança, de mulheres viúvas. O infanticídio é, em geral, precedido por uma tentativa de aborto nos primeiros meses de gravidez. Se a tentativa fracassa, o infanticídio é realizado imediatamente após o parto. É importante considerar que as práticas abortivas são também utilizadas como maneira deliberada de planejar a família e evitar um nascimento indesejado (Junqueira, 1978, 2002).

\section{Discussão e Conclusões}

Em estudo sobre a dinâmica demográfica dos Kamaiurá, Pagliaro e col. (2004) mostraram que entre 1948 e 1966 a população Kamaiurá se manteve estável, em 110 habitantes, devido à alta mortalidade acarretada por epidemias de doenças contagiosas e à manutenção de um padrão de família relativamente pequeno. No período de 1967 a 2002, esses autores registraram um crescimento de 3,5\% dessa população, sendo, em 2002, de 378 habitantes. 0 crescimento vegetativo foi o fator responsável por esse ritmo de crescimento, dado que o saldo migratório resultante de casamentos interétnicos foi negativo nesse período.

Um ritmo de crescimento superior ao dos Kamaiurá vem sendo observado nas últimas décadas em diversas populações indígenas no Brasil e em outras Terras Baixas da América Latina (McSweeney e Arps, 2005). Como exemplo, citamos os Ikpeng e os Kaiabi, habitantes da região central do Parque Indígena do Xingu, que cresceram, respectivamente, $4,9 \%$ e 5,2\%, entre 1970-1999 (Maia e col., 2004; Pagliaro, 2002 e 2005) e os Xavante (Mato Grosso), cujas taxas de crescimento são próximas de 5\% ao ano (Flowers, 1994; Souza e Santos, 2001; Coimbra e col., 2002).

As modificações no padrão demográfico dos Kamaiurá desencadearam-se na década de 1970, quando teve iniciou o processo de declínio da mortalidade, decorrente das medidas médico-sanitárias, implemen- 
tadas de maneira mais sistemática a partir de 1965 , com a implantação de um programa de atenção à saúde dos povos do Parque Indígena do Xingu, coordenado pela Escola Paulista de Medicina, atual Universidade Federal de São Paulo (Rodrigues, 2005; Baruzzi, 2005).

Até 1960, conforme Öberg (1953), Galvão (1979) e Junqueira (1978), os Kamaiurá possuíam um tamanho de família relativamente pequeno, de 2 a 3 filhos, em média. A alta mortalidade, o conhecimento e a adoção de práticas de restrição voluntária da natalidade, como o uso de ervas de efeito contraceptivo, a prática de aborto e de infanticídio, a existência de tabus pósparto e o aleitamento prolongado garantiram a manutenção desse padrão de família por um longo período de tempo.

Este estudo mostrou que, na década de 1970, o nível de fecundidade das mulheres Kamaiurá, medido por meio de Taxas de Fecundidade Total (TFT), atingia 5,7 filhos, em média, por mulher. Na década de 1980, a TFT elevou-se para 6,6 filhos por mulher, declinando ligeiramente para 6,2 filhos em 2000-2003. Apesar de esses valores parecerem bastantes expressivos, o nível de fecundidade das mulheres Kamaiurá demonstrou ser inferior ao estimado entre outros povos habitantes do Parque Indígena do Xingu, como os Kaiabi, por exemplo, cuja TFT, no período 1990-1999, foi de 9,5 filhos em média por mulher (Pagliaro, 2002 e 2005). Entretanto, a fecundidade das mulheres Kamaiurá se assemelharia à das mulheres que se autodeclararam indígenas no Censo Demográfico de 2000 (IBGE, 2005), residentes nas áreas rurais da Região Oeste do Brasil, de 6,9 filhos por mulher. Em relação ao conjunto da população brasileira, a fecundidade das Kamaiurá encontra paralelo com os níveis registrados entre as décadas de 1950 e 1970, quando as TFT no país oscilaram entre 5,8 e 6,3 filhos por mulher. Na atualidade, a TFT no Brasil é de 2,4 filhos por mulher, sendo de 2,3 filhos na região Centro-Oeste do país, onde habitam os Kamaiurá (IBGE, 2004).

Os níveis de fecundidade das mulheres Kamaiurá estariam associados a padrões reprodutivos caracterizados por curtos intervalos de tempo entre os nascimentos, estimados para essas mulheres entre $30 \mathrm{e}$ 36 meses, e ao aleitamento prolongado, que, conforme Junqueira (1978), para os Kamaiurá pode chegar a até três anos. Essa relação também foi encontrada em outras sociedades indígenas no Brasil, como os Mekranoti (Werner, 1983), os Karitiana (Meireles, 1988), os Yanomama do rio Mucajai (Early e Peters, 1990), os Xavante de Pimentel Barbosa (Flowers, 1994; Coimbra e col., 2002) e de Sangradouro-Volta Grande (Souza e Santos, 2001), os Kaiabi (Pagliaro, 2002, 2005) e alguns povos da região do Rio Negro (Azevedo, 2004).

Observou-se também que os Kamaiurá ampliaram o seu tamanho de família sem abandonar as práticas tradicionais de controle da natalidade, sendo favorecidos pelo declínio da mortalidade e o conseqüente aumento da sobrevivência dos filhos. A contribuição da queda da mortalidade para o aumento da média de filhos dessas mulheres pode ser observada por meio da comparação dos indicadores de fecundidade acumulada estimados por Camargo e col. (2005), em 1971 e em 2003, a partir da reconstrução de histórias reprodutivas das mulheres de 15 a 54 anos unidas e sobreviventes nesses anos (Tabela 2).

\section{Tabela 2 - Indicadores de fecundidade acumulada das mulheres Kamaiurá, em 197 I e 2003}

\begin{tabular}{|l|c|c|}
\hline Indicadores & 1971 & 2003 \\
\hline $\mathrm{N}^{\circ}$ de mulheres unidas de $15-54$ anos & 29 & 65 \\
\hline $\mathrm{N}^{\circ}$ de filhos nascidos vivos* & 108 & 263 \\
\hline $\mathrm{N}^{\circ}$ de filhos mortos* & 38 & 21 \\
\hline $\mathrm{N}^{\circ}$ de filhos sobreviventes & 70 & 242 \\
\hline $\mathrm{N}^{\circ}$ médio de filhos nascidos vivos* & 3,7 & 4,3 \\
\hline $\mathrm{N}^{\circ}$ médio de filhos mortos* & 1,3 & 0,3 \\
\hline $\mathrm{N}^{\circ}$ médio de filhos sobreviventes & 2,4 & 4,0 \\
\hline
\end{tabular}

Fontes: Camargo e col., 2005, p. 133.

* Exceto os sacrificados por infanticídio.

Mudanças no tamanho de família podem ser observadas a partir desses dados, tendo o número médio de filhos sobreviventes aumentado de 2,4 para 4, entre 1971 e 2003. Considerando-se os filhos nascidos vivos, não computados os sacrificados por infanticídio, a média de filhos por mulher variou de 3,7 para 4,3 nesse período, tendo a média de filhos mortos diminuído de 1,3 para o,3 por mulher. Esse novo padrão de família refletiria a melhoria das condições de saúde e a queda da mortalidade, decorrente das ações médico-sanitárias levadas a efeito nesse 
período, o que teria garantido, também, o aumento da sobrevivência de recém-nascidos e de crianças na primeira infância.

Ainda no tocante aos fatores que ensejaram modificações no padrão de família dos Kamaiurá, é importante considerar, como referido por Junqueira (1978), um aspecto particularmente significativo da dinâmica populacional desse povo, que diz respeito ao nível de racionalidade com que entendem o processo reprodutivo. $\mathrm{O}$ conhecimento e uso de práticas tradicionais de controle da natalidade, incluindo o aborto e o infanticídio, são exemplos dessa racionalidade. Para os Yanomama do rio Mucajai, Early e Peters (1990) também observaram a existência da prática de aborto e infanticídio. Assim como Junqueira observou para os Kamaiurá (1978), esses autores relatam que os Yanomama consideram o infanticídio um aborto terminal e não um homicídio. A maioria das vezes em que apelam para o infanticídio, a rejeição do bebê, independentemente do sexo, é a causa mais freqüente, podendo ocorrer em razão do curto espaçamento entre os filhos, do nascimento de gêmeos, de deformidades físicas, de ausência de marido, de separações e viuvez, e, para selecionar o sexo dos filhos (Santos e col., 2005).

Além do efeito provocado pela melhoria das condições de saúde e pela queda da mortalidade, a elevação do nível de fecundidade das mulheres Kamaiurá a partir dos anos de 1970 poderia ser também mais um indício da intencionalidade na condução da sua reprodução biológica. Um inquérito realizado por Junqueira (1978), em 1971, já apontava para a intenção dos Kamaiurá em aumentar o tamanho de suas famílias para um número ideal de filhos que se situava entre 3,7 para os homens e 5,1 para as mulheres. Conforme a autora, as motivações a respeito do tamanho de família e dos motivos que justificariam sua ampliação, ou diminuição deixavam transparecer um estilo de controle racional. Para os homens, o desejável aumento do tamanho da família ligava-se especialmente às funções de liderança, à idéia de que a expansão demográfica seria condição da sobrevivência do grupo e da realização mais completa de suas aspirações culturais. Um tamanho maior de família seria também justificado em termos dos papéis de proteção e de segurança que os filhos poderiam representar em relação aos pais (Camargo e col., 2005).
Este estudo mostrou também que a partir da década de 1990 houve um envelhecimento do padrão reprodutivo das mulheres Kamaiurá, evidenciado pela diminuição dos níveis de fecundidade das mulheres com até 24 anos e pelo aumento entre as mulheres de 25 a 34 anos. Isso poderia indicar que, ampliado o tamanho de família e visando contornar os efeitos do aumento da sobrevivência dos filhos, os Kamaiurá estariam postergando o início das uniões, lançando mão do uso mais intensivo das práticas tradicionais de controle da natalidade, como o aborto e o infanticídio. Corrobora com esta afirmação a elevada proporção de mulheres com 15 anos de idade ou mais que permaneciam solteiras em 2003 (26\%), proporção muito superior ao observado por Junqueira em 1971 (1978), que era de 6,3\%. Da mesma forma, o aumento da média de idade ao nascimento do primeiro filho, de 16,2 anos na década de 1970, para 18,8 anos, em 2000-2003, seria consoante com o envelhecimento do padrão reprodutivo verificado.

A análise desses dados conduz à discussão acerca da relação entre sistemas culturais e padrões demográficos dos povos indígenas, além de nos colocar diante de uma complexa discussão que diz respeito à racionalidade com que esses povos conduzem o processo reprodutivo. Acredita-se que, os Kamaiurá, que tradicionalmente tinham poucos filhos, foram favorecidos pelo declínio da mortalidade, e que, sem abandonar suas práticas tradicionais de controle da natalidade, ampliaram o seu tamanho tradicional de família e o seu volume populacional de forma equilibrada, viabilizando assim a conquista de um lugar de destaque no cenário político do Alto Xingu.

\section{Agradecimentos}

Aos Kamaiurá, pela colaboração na realização desta pesquisa.

\section{Referências}

AZEVEDO, M. M. Demografia dos povos indígenas do Alto Rio Negro, Amazonas: um estudo de caso de nupcialidade e reprodução. 2004. Tese (Doutorado em Demografia) - Instituto de Filosofia e Ciências Humanas da Universidade Estadual de Campinas, Campinas, 2004. 
BARUZZI, R. G. Do Araguaia ao Xingu. In: BARUZZI, R. G.; JUNQUEIRA, C. (Org.). Parque Indígena do Xingu: saúde, cultura e história. São Paulo: Terra Virgem, 2005. p. 59-112.

CAMARGO, C. P. F.; JUNQUEIRA, C.; PAGLIARO, H. Reflexões acerca do mundo cultural e do comportamento reprodutivo dos Kamaiurá ontem e hoje. In: PAGLIARO, H.; AZEVEDO, M. M.; SANTOS, R. V. (Org.). Demografia dos povos indígenas no Brasil. Rio de Janeiro: Fiocruz: ABEP, 2005. p. 119-134.

COIMBRA, C. E. A. J. et al. The Xavánte in transition: health, ecology, and bioanthropology in Central Brazil. Ann Arbor: University of Michigan, 2002.

DAS GUPTA, M. Kinship systems and demography regimes. In: KERTZER, D. I.; FRICKE, T. (Org.).

Anthropological demography: toward a new synthesis. Chicago: University of Chicago, 1997. p. 36-52.

DAVIS, K.; BLAKE, J. La estructura social y la fecundidad: un sistema analítico. In: FREEDMAN, R. (Org.). Factores sociologicos de la fecundidad. México, DF: CELADE, 1967, p. 156-197.

EARLY, J. D.; PETERS, J. F. The population dynamics of the Mucajai Yanomama. New York: Academic Press, 1990.

FLOWERS, N. M. Crise e recuperação demográfica: os Xavánte de Pimentel Barbosa, Mato Grosso. In: SANTOS, R. V.; COIMBRA JR, C. E. (Org.). Saúde dos povos indígenas. Rio de Janeiro: Fiocruz, 1994. p. 213242.

FUNAI - FUNDAÇÃO NACIONAL DO ÍNDIO. Disponível em: <www.funai.gov.br>. Acesso em: 5 mar. 2006.

GALVÃO, E. Encontro de sociedades: índios e brancos no Brasil. Rio de Janeiro: Paz e Terra, 1979. (Coleção Estudos Brasileiros, 29).

GOMES, M. P. Os índios e o Brasil: ensaio sobre um holocausto e sobre uma nova possibilidade de convivência. Petrópolis: Vozes, 1991.

GOMES, M. P. $O$ índio na história: o povo Tenetehara em busca da liberdade. Petrópolis: Vozes, 2002.

GREENE, M. E.; CROCKER, W. H. Some demografic aspects of the Canela indians of Brazil. South American Indian Studies, Bennington, v. 4, 1994. p. 47-62.
HEMMING, J. The red gold: the conquest of the Brazilian indians. London: Macmillan London, 1978.

IBGE - INSTITUTO BRASILEIRO DE GEOGRAFIA E ESTATÍSTICA. Tendências demográficas: uma análise dos resultados da amostra do censo demográfico 2000. Rio de Janeiro, 2004. (Coleção Estudos \& Pesquisas, 13).

IBGE - INSTITUTO BRASILEIRO DE GEOGRAFIA E ESTATÍSTICA. Tendências demográficas: uma análise dos indígenas com base nos resultados da amostra dos censos demográficos 1991 e 2000. Rio de Janeiro, 2005. (Coleção Estudos \& Pesquisas, 16).

JUNQUEIRA, C. Os índios do Ipavu: um estudo sobre a vida do grupo Kamaiurá. São Paulo: Ática, 1978.

JUNQUEIRA, C. Sexo e desigualdade entre os Kamaiurá e os Cinta Larga. São Paulo: Olho Dágua: CAPES, 2002.

KENNEDY, D. P.; PERZ, S. G. Who are Brazil's indígenas?: contributions of census datas analyses to anthropological demography of indigenous populations. Human Organization, Washington, DC, n. 59, p. 311-324, 2000.

MAIA, S. F. et al. A recuperação populacional dos Txicão (Ikpeng), Parque Indígena do Xingu, Mato Grosso, Brasil. In: ENCONTRO NACIONAL DE ESTUDOS POPULACIONAIS DA ABEP, 14., 2004, Caxambu. Anais... Caxambu: ABEP, 2004. Disponível em: <www.abep.org.br . Acesso em: 25 maio 2006.

MCSWEENEY, K.; ARPS, S. A demographic turnaround: the rapid growth of indigenous populations in Lowland Latin America. Bulletin of Latin American Research Review, Oxford, v. 18, n. 1, fev. 2005 .

MEIRELES, D. M. Sugestões para uma análise comparativa da fecundidade em populações indígenas. Revista Brasileira de Estudos Populacionais, São Paulo, v. 5, n. 1, p. 1-20, 1988.

MELATTI, J. C. Crescimento populacional. Brasil Indígena, Brasília, DF, v. 1, n. 1, p. 24-25, 1999.

ÖBERG, K. Indian tribes of Northern Mato Grosso, Brasil. Washington, DC: Smithsonian Institution, 1953. (Institute of Social Anthropology, 15). 
PAGLIARO, H. A revolução demográfica dos povos indígenas no Brasil: a experiência dos Kaiabi do Parque Indígena do Xingu, Mato Grosso, Brasil 1970-1999. 2002. Tese (Doutorado em Saúde Publica) - Faculdade de Saúde Pública da Universidade de São Paulo, São Paulo, 2002.

PAGLIARO, H.; AZEVEDO, M. M.; SANTOS, R. V. Demografia dos povos indígenas no Brasil: um panorama critico. In: PAGLIARO, H; AZEVEDO, M. M.; SANTOS, R. V. (Org.). Demografia dos povos indígenas no Brasil. Rio de Janeiro: FIOCRUZ: ABEP, 2005. p. 11-32.

PAGLIARO, H. et al. Comportamento demográfico dos Kamaiurá, Parque Indígena do Xingu, Mato Grosso, Brasil (1970-1999). In: ENCONTRO NACIONAL DE ESTUDOS POPULACIONAIS DA ABEP, 14., 2004, Caxambu. Anais... Caxambu: ABEP, 2004. Disponível em: <www.abep.org.br $>$. Acesso em: 16 jul. 2006.

PICCHI, D. Observations about a Central Brazilian indigenous population: the Bakairi. South American Indian Studies, Bennington, v. 4, p. 37-46, 1994.

RICARDO, C. A. (Org.). Povos indígenas no Brasil 1996/20oo. São Paulo: Instituto Socioambiental, 2000.

RIBEIRO, D. Convívio e contaminação: efeitos dissociativos da depopulação provocada por epidemias em grupos indígenas. Sociologia, São Paulo, v. 18, n. 1, p.3-50, 1956.

RIBEIRO, D. Culturas e línguas indígenas do Brasil. Educação e Ciências Sociais, Rio de Janeiro, v. II, n. 6, p. 4-102, 1957.
RODRIGUES, D. A UNIFESP/Escola Paulista de Medicina, o Projeto Xingu e a política de atenção a saúde dos povos indígenas no Brasil. In: BARUZZI, R. G.; JUNQUEIRA, C. (Org.). Parque Indígena do Xingu: saúde, cultura e historia. São Paulo: Terra Virgem, 2005. p. 259-273.

SANTOS, R. V.; PAGLIARO, H.; AZEVEDO, M. M. A dinâmica demográfica dos Mucajai Yanomama: uma entrevista com John Early. In: PAGLIARO, H., AZEVEDO, M. M.; SANTOS, R. V. (Org.) Demografia dos povos indígenas no Brasil. Rio de Janeiro: FIOCRUZ: ABEP, 2005. p. 167-192.

SOUZA, L. G.; SANTOS, R. V. Perfil demográfico da população indígena Xavánte de Sangradouro - Volta Grande, Mato Grosso (1993-1997), Brasil. Cadernos de Saúde Pública, Rio de Janeiro, v. 17, n. 2, p. 355366, 2001.

STEINEN, K. V. D. Entre os aborígenes do Brasil central. Revista do Arquivo, São Paulo, n. 34 e 58, p. 707, set. 1940 .

VILLAS BÔAS, O.; VILLAS BÔAS, C. A marcha para o oeste. Rio de Janeiro: Globo, 1994.

WAGLEY, C. Os efeitos do despovoamento sobre a organização social entre os índios Tapirapé. Sociologia, São Paulo, v. IV, n. 4, p. 407-411, 1942.

WAGLEY, C. Cultural influences on population: a comparison of two Tupi tribes. Revista do Museu Paulista, São Paulo, n. 5, p. 95-104, 1951.

WERNER, D. Fertility and pacification among the Mekranoti of Central Brazil. Human Ecology, New York, v. 11, n. 2, p. 227-245, 1983. 